\title{
Gas-Liquid Flow and Interphase Mass Transfer in LL Microreactors
}

\author{
Brendon J. Doyle ${ }^{1}$, Frederic Morin ${ }^{1}$, Jan B. Haelssig ${ }^{2}$, Dominique M. Roberge ${ }^{3, *}$ and \\ Arturo Macchi ${ }^{1, *}$ iD \\ 1 Centre for Catalysis Research and Innovation, Department of Chemical and Biological Engineering, \\ University of Ottawa, Ottawa, ON K1N 6N5, Canada; bdoyl042@uottawa.ca (B.J.D.); \\ fmori017@uottawa.ca (F.M.) \\ 2 Department of Process Engineering and Applied Science, Dalhousie University, \\ Halifax, NS B3H 4R2, Canada; Jan.Haelssig@dal.ca \\ 3 API Development Services, Lonza AG, CH-3930 Visp, Switzerland \\ * Correspondence: dominique.roberge@lonza.com (D.M.R.); arturo.macchi@uottawa.ca (A.M.)
}

Received: 30 October 2020; Accepted: 26 November 2020; Published: 28 November 2020

\begin{abstract}
This work investigates the impact of fluid $\left(\mathrm{CO}_{2(\mathrm{~g})}\right.$, water) flow rates, channel geometry, and the presence of a surfactant (ethanol) on the resulting gas-liquid flow regime (bubble, slug, annular), pressure drop, and interphase mass transfer coefficient $\left(k_{l} a\right)$ in the FlowPlate ${ }^{\mathrm{TM}}$ LL (liquid-liquid) microreactor, which was originally designed for immiscible liquid systems. The flow regime map generated by the complex mixer geometry is compared to that obtained in straight channels of a similar characteristic length, while the pressure drop is fitted to the separated flows model of Lockhart-Martinelli, and the $k_{l} a$ in the bubble flow regime is fitted to a power dissipation model based on isotropic turbulent bubble breakup. The LL-Rhombus configuration yielded higher $k_{l} a$ values for an equivalent pressure drop when compared to the LL-Triangle geometry. The Lockhart-Martinelli model provided good pressure drop predictions for the entire range of experimental data (AARE $<8.1 \%$ ), but the fitting parameters are dependent on the mixing unit geometry and fluid phase properties. The correlation of $k_{l} a$ with the energy dissipation rate provided a good fit for the experimental data in the bubble flow regime (AARE $<13.9 \%$ ). The presented experimental data and correlations further characterize LL microreactors, which are part of a toolbox for fine chemical synthesis involving immiscible fluids for applications involving reactive gas-liquid flows.
\end{abstract}

Keywords: microreactor; gas-liquid flow; flow regime; pressure loss; interphase mass transfer; $\mathrm{CO}_{2}$ absorption

\section{Introduction}

Process intensification via miniaturization is a method of rendering reactors more efficient, economical, environmentally friendly, and safer through a reduction in volume. The smaller length scales enhance heat and mass transfer rates by providing greater vessel specific areas and reducing transport distances. These improvements in transport rates, as well as the smaller working volumes, allow highly exothermic reactions to be run safely with less dilution and better yields [1]. In particular, continuously operated micro- and milli-scale reactors offer these advantages at production rates relevant to the pharmaceutical industry, which are typically less than $600 \mathrm{~g} / \mathrm{min}$ [2]. In multiphase systems, small reactor dimensions have the added benefit of creating more consistent dispersions (e.g., segmented flow) and higher interfacial areas, which yield higher and more predictable mass transfer rates [3]. However, continuous-flow microreactor technology is still a relatively young field. Therefore, 
further characterization must be performed for different types of reactors and fluids systems to enable process design and thereby drive more widespread use.

Several gas-liquid microreactor technologies (e.g., falling films, static mixers, tubular, membranes, packed beds) have been proposed for various applications and production rates [4,5]. In particular, the Corning ${ }^{\mathrm{TM}}$ Advanced-Flow ${ }^{\mathrm{TM}}$ reactor with heart-shaped mixing structures [6-8] and the FlowPlate ${ }^{\mathrm{TM}}$ reactor with LL (liquid-liquid) structures $[9,10]$ can operate at relatively high throughputs and use Venturi-like contractions followed by chambers containing flow-impinging obstacles in order to change the magnitude and direction of the flow field. Specifically, the LL mixer focuses the immiscible fluids onto an obstacle that breaks the dispersed phase and desynchronizes the fragments. Variable volume chambers and non-symmetrical rhomboidal or triangular obstacles with varying orientations at each consecutive mixing unit act together to reduce re-coalescence. The FlowPlate ${ }^{\mathrm{TM}}$ reactor is offered in a variety of mixer and plate sizes rated for different flow rate ranges [11].

In gas-liquid reactions, the flow morphology has a determining impact on the specific area available for interphase mass transfer and on the pressure drop. Although many flow regimes have been identified, this work focuses on three main regimes: bubble flow, slug flow, and annular flow. Many methods for identifying these flow regimes have been used in the past, with the simplest being visual identification [12]. Additionally, several mechanisms have been proposed to predict the conditions under which flow regime transitions occur $[13,14]$, but agreement over a large range of fluid physical properties and channel geometries has been poor [15]. For this reason, the comparison of empirically determined regime transitions from similar systems has been preferred by some authors [12-16] and will be used in this study.

Previous work has demonstrated the applicability of LL-Reactors for liquid-liquid systems with varying physical properties over a range of production rates relevant to the pharmaceutical industry $[17,18]$. It was shown that a two-phase flow regime identification via visualization is crucial in understanding changes in the interphase mass transfer rates with flow rate, allowing for the development of an effective scale-up methodology $[9,17,18]$. In particular, in liquid-liquid systems, the onset of the drop flow, which is analogous to bubble flow in gas-liquid systems, was identified as a key parameter in scale-up, since the interphase mass transfer rates depend on the energy dissipation rate resulting from chaotic advection and not on reactor geometry in this regime [18]. As such, the aim of this work is to investigate the applicability of LL-Reactors in gas-liquid systems by identifying key performance parameters in order to advance the toolbox approach developed by Plouffe et al. [10], as has been done for liquid-liquid reactions. First, the flow regimes are visually identified; next, the two-phase pressure drops over the length of the reactor are measured and analyzed; then, the mass transfer rates are measured using physical $\mathrm{CO}_{2}$ absorption experiments, and the data are analyzed and correlated in terms of a volumetric mass transfer coefficient $\left(k_{l} a\right)$. The analysis includes a range of gas and liquid flow rates, LL-Reactors using a rhombus or triangle as the obstacle, and a liquid phase with or without the addition of a surfactant.

\section{Materials and Methods}

A schematic of the experimental set-up is presented in Figure 1. The gas and liquid were fed continuously into the microreactor system via a Bronkhorst ${ }^{\mathrm{TM}}$ mini CORI-FLOW ${ }^{\mathrm{TM}}$ M12V10I mass flow controller (MFC) with an accuracy of $\pm 0.5 \%$ of flow rate and a HiTec Zang SyrDos ${ }^{\mathrm{TM}} 2$ syringe pump equipped with $25 \mathrm{~mL}^{\mathrm{DURAN}}{ }^{\mathrm{TM}}$ borosilicate glass syringes, respectively. The microreactor system utilizes a FlowPlate ${ }^{\mathrm{TM}}$ Lab manufactured by Ehrfeld Mikrotechnik $\mathrm{GmbH}$, which features a quartz viewing glass. Each reactor plate consists of a series of 21 micromixers machined into a size ISO 216 A7 $(74 \times 105 \mathrm{~mm})$ Hastelloy ${ }^{\mathrm{TM}} \mathrm{C}-22^{\mathrm{TM}}$ plate, with a total reaction zone volume of $0.95 \mathrm{~mL}$. The characteristic lengths of the mixing units are taken at the contraction, where the width $(w)$ is $0.5 \mathrm{~mm}$ and the depth $(\delta)$ is $1.25 \mathrm{~mm}$, resulting in a hydraulic diameter $\left(d_{h}\right)$ of $0.714 \mathrm{~mm}$. The mixer arrangement and geometry are presented in Figure 2. Two mixer geometries were used-the LL-Rhombus and 
LL-Triangle-which differ only in the geometry of the obstacle. Both FlowPlates ${ }^{\mathrm{TM}}$ were operated horizontally and at ambient temperature $\left(25^{\circ} \mathrm{C}\right)$.

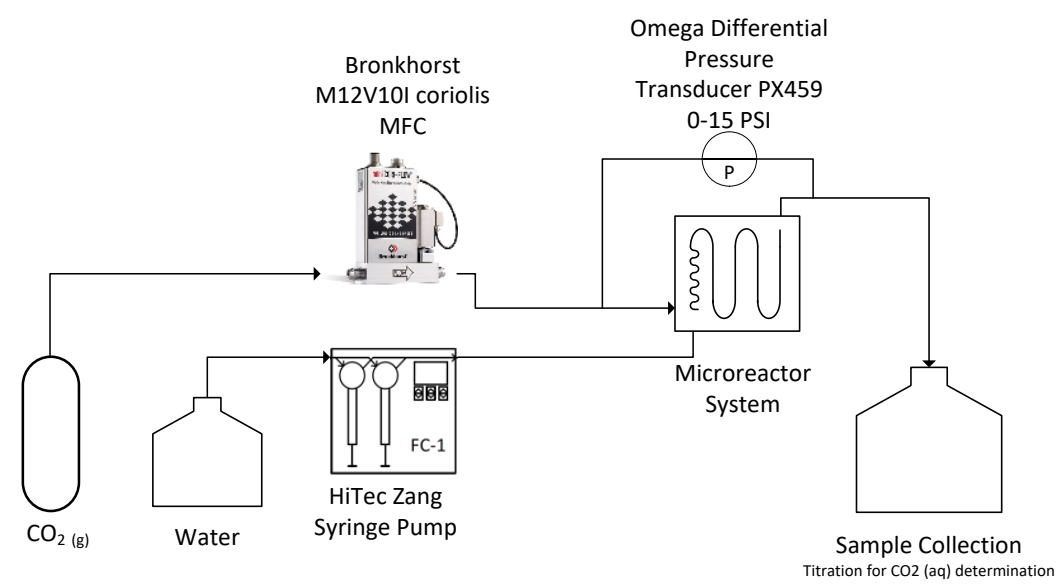

Figure 1. Set-up of flow visualization, pressure drop, and interphase mass transfer experiments.

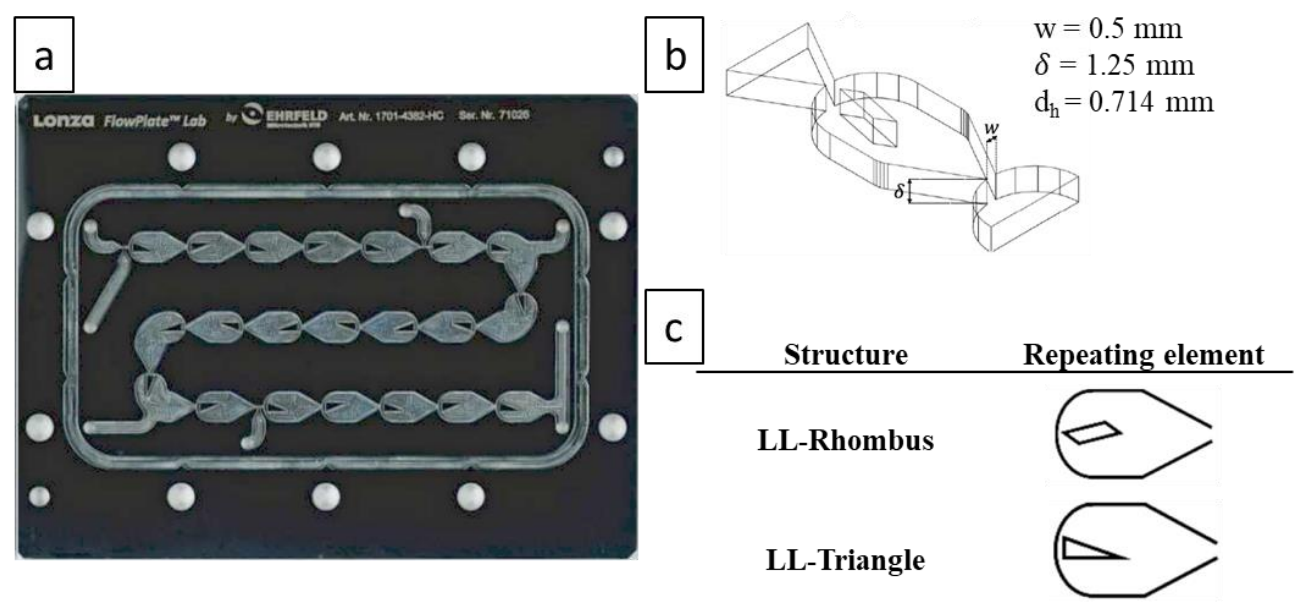

Figure 2. Geometry of FlowPlate ${ }^{\mathrm{TM}}$ and mixing elements: (a) LL (liquid-liquid)-Reactor (triangle) size A7 plate arrangement [17] (licensed under https://creativecommons.org/licenses/by/4.0/); (b) three-dimensional visualization and characteristic dimensions of the (rhombus) mixing element; and (c) repeating mixing elements in the LL-Rhombus and LL-Triangle [17] (licensed under https://creativecommons.org/licenses/by/4.0/).

The gas used is carbon dioxide ( $\geq 99.99 \mathrm{vol} \%$, Linde AG), while the liquid was either deionized water or a $0.5 \mathrm{wt} \%$ ethanol in water solution to investigate the impact of surfactant on the flow morphology and resulting transport phenomena. The ethanol concentration is sufficient to inhibit bubble coalescence [19], but still low enough not to significantly change the liquid equilibrium physical properties [20]. In practice, it may not be possible to know the type and amount of surface-active species present in the liquid. Thus, this approach provides relative effects between two gas-liquid systems with different degrees of bubble coalescence inhibition in order to better anticipate the resulting trends in flow regime boundaries and the associated pressure drop and interphase mass transfer.

The visualizations of the flow regimes were recorded with a camera through the viewing glass on the microreactor. Pressure measurements were taken and averaged over the course of $5 \mathrm{~min}$ at the gas inlet and reactor outlet using an Omega PX459 differential pressure transducer (15 $\pm 0.012 \mathrm{psi}$ ) and a HiTec Zang LabBox ${ }^{\mathrm{TM}} 3 \mathrm{M}$ data collection system in order to determine the pressure drop across the reactor. Interphase mass transfer rates were determined using physical $\mathrm{CO}_{2}$ absorption experiments. The $\mathrm{CO}_{2}$ concentrations in the liquid feed and outlet were measured via the Warder titration [21] of 
$5 \mathrm{~mL}$ samples with phenolphthalein and methyl orange indicators after the system had reached steady state, as observed by a constant pressure drop.

The liquid feed flow rate was varied from 5 to $40 \mathrm{~mL} / \mathrm{min}$ and the gas feed flow rate was varied from 0.5 to $40 \mathrm{~g} / \mathrm{h}$ for $\mathrm{CO}_{2}$-deionized water flowing through the LL-Rhombus, whereas the impact of obstacle geometry and surfactant were conducted at liquid flow rates of 10 and $20 \mathrm{~mL} / \mathrm{min}$. Average gas velocities between the reactor inlet and outlet are reported throughout, considering the consumption of $\mathrm{CO}_{2}$ via absorption (up to $73 \%$ at lower gas flow rates) and gas expansion due to pressure losses (up to 0.44 bar). The superficial velocities are based on the mixer contraction cross-sectional area, which is where the kinetic energy is greatest.

\section{Results}

\subsection{Flow Regimes}

In the flow regime identification, the first few mixers were ignored, since flow typically does not develop fully until the end of the first row of mixers. Regimes are shown in Figure 3 and were identified as one of the following based on distinct criteria: bubble flow, where gas bubbles are nearly spherical with a diameter less than half the mixer's largest width; slug flow, where the gas bubbles are nearly the mixer's width and elongated; and annular flow, where an uninterrupted gas core surrounded by a liquid film spans the length of the reactor (after flow is established following the first row of mixers). The bubble flow regime thus includes dispersed bubble flow and bubbly flow, while the annular flow regime comprises the slug-annular and churn flow regimes used by Triplett et al. [22], since differentiating between different annular sub-regimes is difficult for the scales and geometries of the mixers. Flow may also exhibit the characteristics of two or more flow regimes, whether in one region over a span of time or in many regions at a given time, especially near transition boundaries, so "mixed" regimes are therefore identified where necessary.
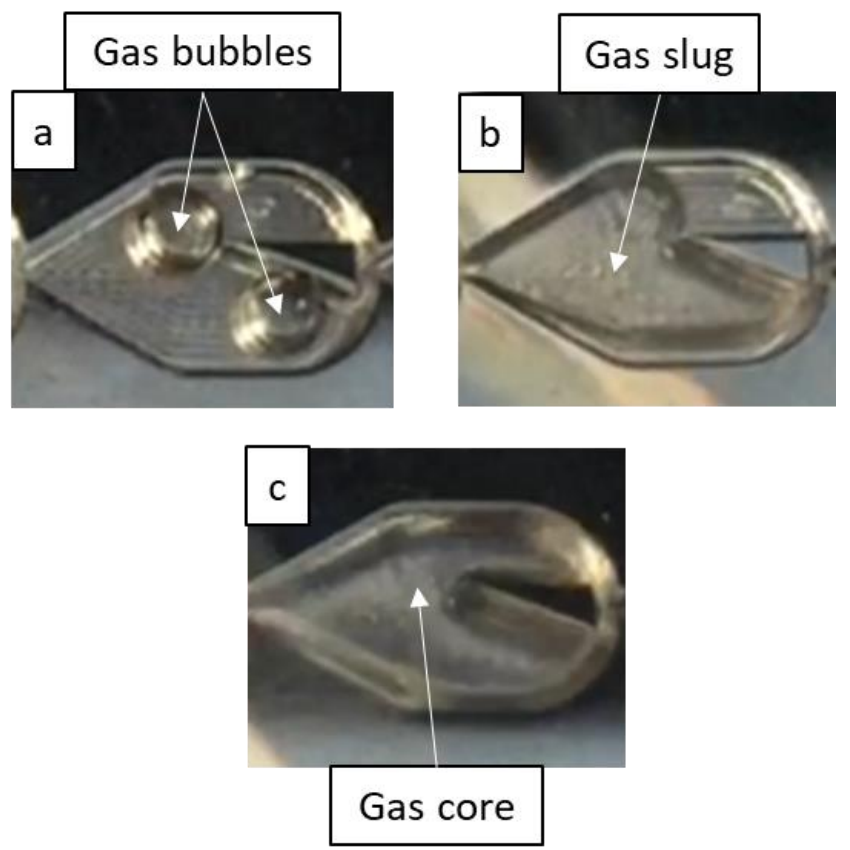

Figure 3. Flow regimes identified in this work. (a) Bubble flow, (b) slug flow, (c) annular flow.

In larger-scale channel flows, gravitational effects have a significant impact on the two-phase flow. However, in microchannels the interfacial tension and wetting properties are dominant compared to gravitational forces, and the flow may be treated as if it were under microgravity conditions. This means that the flow is independent of the channel orientation and that flow regimes caused by 
gravity-induced phase separation will not occur. Ullmann and Brauner [13] propose that Eo $\lesssim 1.6$ as the requisite condition for using microchannel models. From Equation (1), the Eötvös number at the widest part of the LL mixers used in this work is $\sim 0.85$ (width and depth of 5 and $1.25 \mathrm{~mm}$, respectively), satisfying the condition for pseudo-microgravity flow and indicating that flow regime transitions should be treated as such.

$$
E o=\frac{\Delta \rho g \delta w}{\sigma}
$$

\subsubsection{Effect of Gas and Liquid Flow Rates}

Figure 4 presents flow regime maps prepared for the LL-Rhombus and LL-Triangle geometries using the coordinates of gas and liquid superficial velocities, with the transition lines of Triplett et al. [22] for air-water flow in a $1.097 \mathrm{~mm}$-diameter circular microchannel $(E o \approx 0.16)$ superimposed as reference. The flow regime map of Triplett et al. [22] has served as a basis of comparison for many authors, including Yue et al. [16], who used a rectangular microchannel with a hydraulic diameter of $0.667 \mathrm{~mm}$ with a $\mathrm{CO}_{2}$-water fluid system $(E o \approx 0.067)$. Notable deviations from the transition boundaries of Triplett et al. [22] include an onset of bubble flow from slug flow at lower liquid velocities in the LL-Reactors and the presence of the annular flow regime at lower gas flow rates in the LL-Rhombus than in the LL-Triangle.
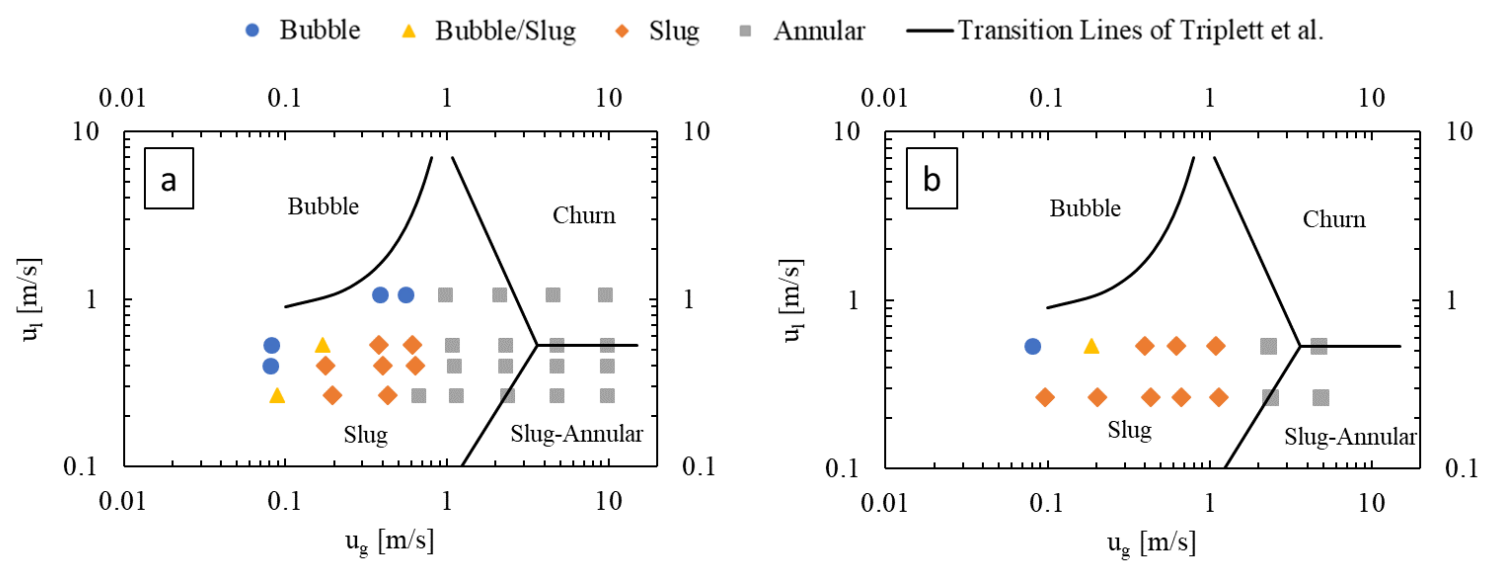

Figure 4. Flow regime maps of (a) LL-Rhombus and (b) LL-Triangle, with deionized water as liquid phase.

Bubble flow can also be less predominant in the LL-Triangle than in the LL-Rhombus since the flat wall of the triangular obstacle impinges on incoming flow and abruptly redirects it toward the curved sides of the mixer [17]. Centrifugal forces then push the denser liquid phase toward the walls of the mixer, creating a greater gas holdup in the center of the mixer. Furthermore, the shape of the triangle will create a larger fluid recirculation zone beside the hypotenuse of the right triangle obstacle than is generated along the long leeward side of the rhombus. The combination of the sharper redirection of the flow and the larger recirculation zone on the leeward side of the obstacle promotes bubble coalescence, as shown in Figure 5. Note that the gas bubble attached to the triangle obstacle remains fixed over time, suggesting that parallelization of gas and liquid flows is present. In contrast, the narrow point of the rhombus obstacle causes a more gradual flow redirection and less opportunity for re-coalescence.

Furthermore, the annular flow regime occurs at greater gas velocities in the LL-Triangle than in the LL-Rhombus due to the aforementioned impingement caused by the flat face of the triangle. Annular flow occurs when the inertia of the gas core is strong enough to overcome interfacial tension forces, among other factors [13]. When the fluids collide with the triangular obstacle, energy from the flow is dissipated into chaotic eddies that deform the gas-liquid interface. The resulting disruption of the gas core causes the slug-to-annular transition to shift to higher gas velocities in the LL-Triangle 
than in the LL-Rhombus, where the sharp and relatively narrow point of the rhombus causes less disruption in flow.
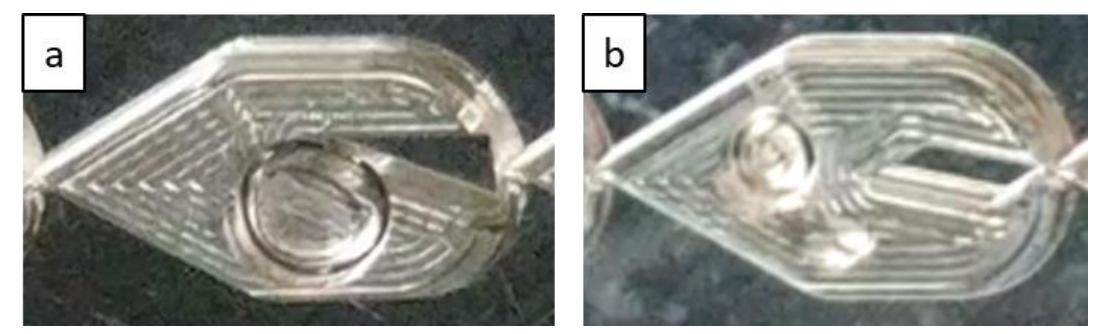

Figure 5. Flow in LL-Triangle (a) demonstrating increased gas holdup in the center of the mixer, a behavior that is absent in the LL-Rhombus (b) under the same flow rates. Liquid velocity is $0.53 \mathrm{~m} / \mathrm{s}$, and gas velocity is $0.080 \mathrm{~m} / \mathrm{s}$ in the LL-Triangle and $0.081 \mathrm{~m} / \mathrm{s}$ in the LL-Rhombus.

\subsubsection{Effect of Surfactant}

When the aqueous $0.5 \mathrm{wt} \%$ ethanol solution was used as the liquid phase, bubble flow was the dominant two-phase flow regime, being present at all the tested flow rate pairings, as shown in Figure 6 . This is due to the surfactant decreasing surface forces, which promotes bubble breakage, as well as forming a film at the gas-liquid interface that inhibits bubble coalescence (Gibbs-Marangoni effect), thereby allowing bubble flow to persist at lower liquid velocities (i.e., lower energy input). At greater gas velocities, the encountered bubble flow resembled a froth that appears to move as a single fluid, as shown for the LL-Triangle geometry in Figure 7.

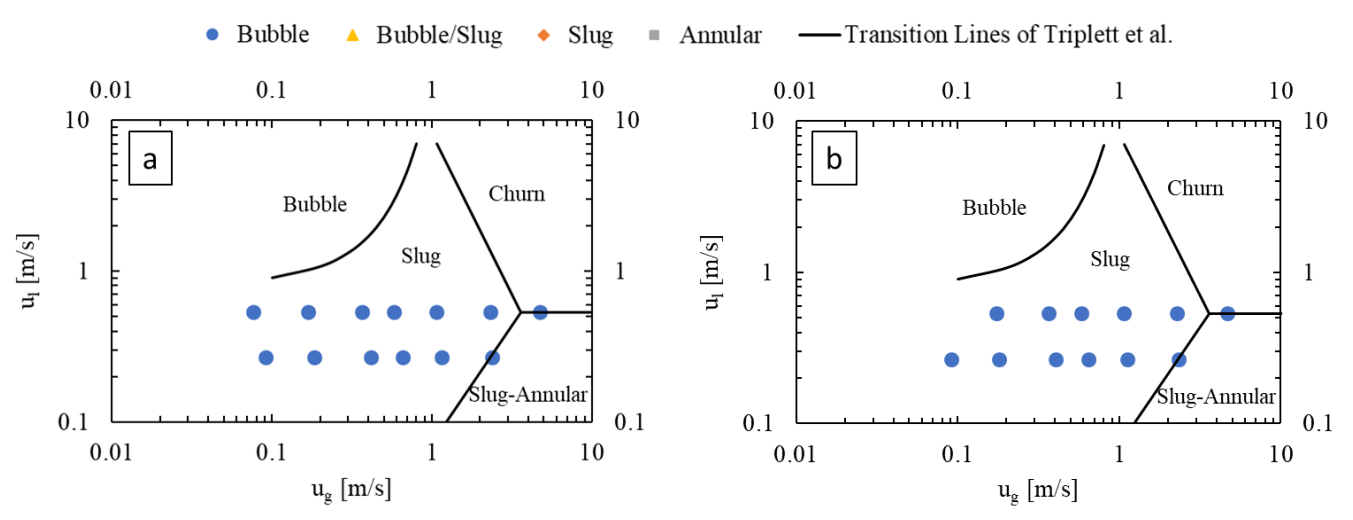

Figure 6. Flow regime maps of (a) LL-Rhombus and (b) LL-Triangle, with $0.5 \mathrm{wt} \%$ aqueous ethanol solution as the liquid phase.

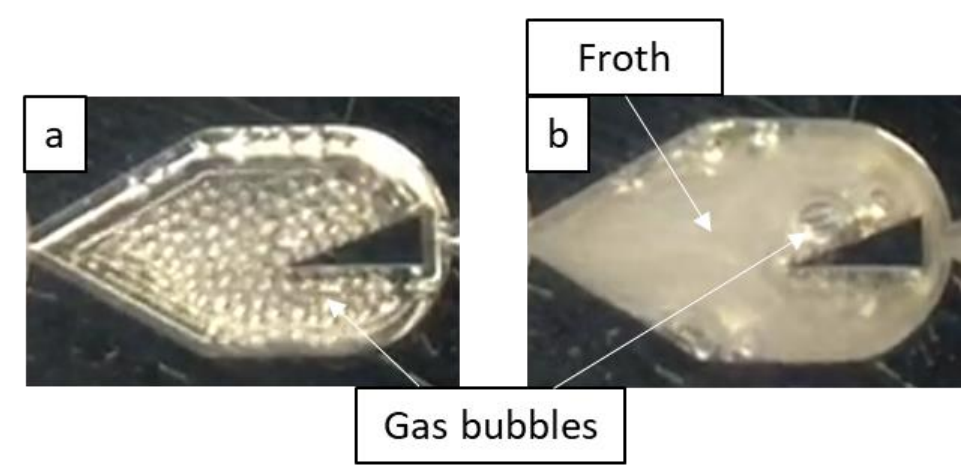

Figure 7. Flow in the LL-Triangle mixer demonstrating the effect of an increased gas flow rate on the flow morphology where surfactant is present. Gas velocities are (a) $0.091 \mathrm{~m} / \mathrm{s}$ and (b) $0.65 \mathrm{~m} / \mathrm{s}$, and the liquid velocity is $0.27 \mathrm{~m} / \mathrm{s}$. Note that (a) demonstrates bubble flow, and (b) demonstrates bubble flow with froth formation. 


\subsection{Pressure Drop}

\subsubsection{Impact of Operating Conditions}

For deionized water as the liquid phase, as shown in Figure 8a, the pressure drop was found to increase with the liquid and gas velocities, although the liquid flow has a more prominent effect. Furthermore, the two-phase pressure drops remain greater for the LL-Triangle compared to the LL-Rhombus due to the impingement of flow against the flat face of the triangular obstacle and because the triangle forms a longer narrow flow channel with the outer wall of the mixing unit. In both LL-plates, the increase in pressure drop with increasing gas flow rate is initially more rapid followed by a decrease in slope that generally coincides with the transitions to slug or annular flow, as seen in Figure 4.

An increase in the gas or liquid velocities also raises the pressure drop when using the aqueous ethanol solution, as shown in Figure 8b, but the impact of liquid velocity is lower. Furthermore, the effect of obstacle geometry is rendered marginal, and the abrupt slope decrease with increasing gas velocity is generally not observed due to the employed range of gas and liquid velocity combinations resulting only in bubble flow (Figure 6). The pressure drop was also generally greater when the surfactant was present, especially at higher gas velocities, since many small bubbles results in a frothy mixture, which would increase the effective drag force between the gas and liquid phases and therefore lead to a higher local liquid velocity.
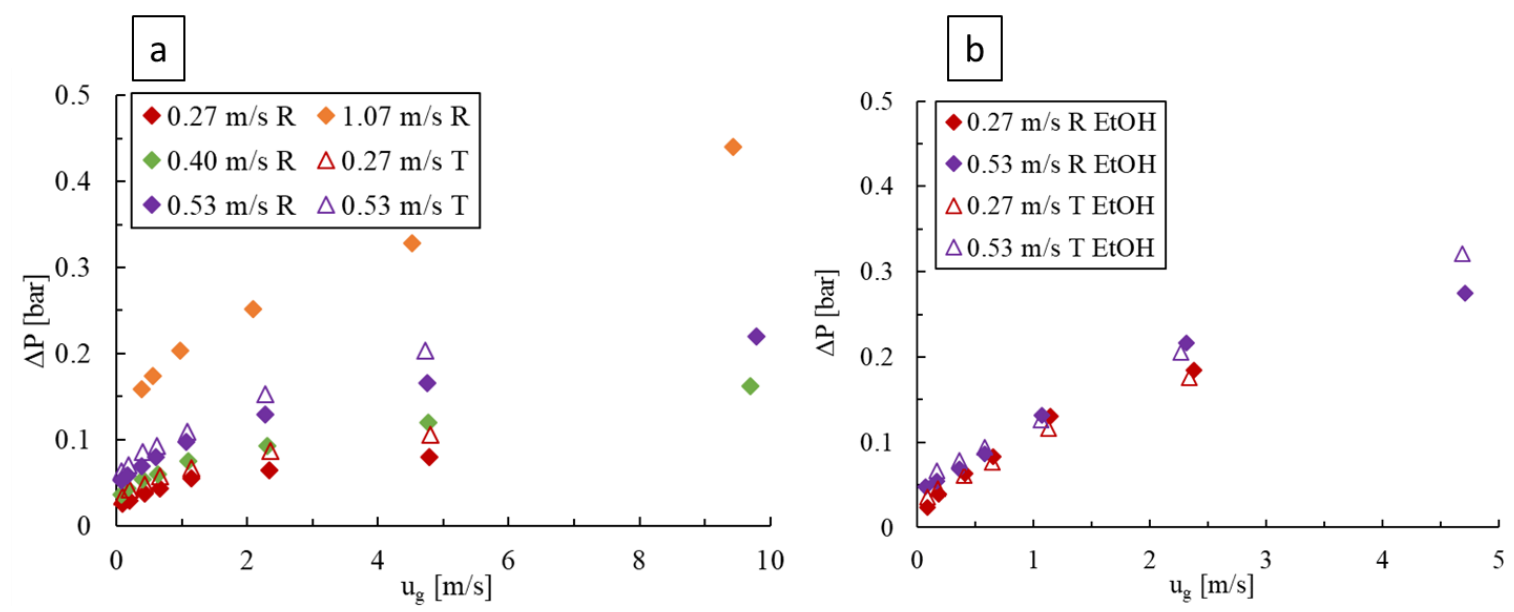

Figure 8. Pressure drop over varying liquid and gas velocities in the LL-Rhombus (R) and LL-Triangle (T) reactors with (a) water and (b) $0.5 \mathrm{wt} \%$ aqueous ethanol as the liquid phase.

\subsubsection{Model}

The data from both the water and aqueous ethanol solution were fitted to the two-phase flow model of Lockhart-Martinelli [23], which adds a two-phase friction multiplier, $\phi^{2}$, to the pressure drop gradient of a single phase, as seen in Equation (2). The two-phase friction multiplier is a function of the Martinelli parameter, $\chi$, and of the Chisholm parameter, Ch (Equations (3) and (4)). Since liquid is the wetting phase of the reactor and has the greater pressure-drop gradient, this phase and its associated friction multiplier $\phi_{l}^{2}$ were chosen for the model.

$$
\begin{aligned}
\left(\frac{\Delta p}{\Delta L}\right)_{T P F} & =\phi_{l}^{2}\left(\frac{\Delta p}{\Delta L}\right)_{l}=\phi_{g}^{2}\left(\frac{\Delta p}{\Delta L}\right)_{g} \\
\phi_{l}^{2} & =1+\frac{C h}{\chi}+\frac{1}{\chi^{2}}
\end{aligned}
$$




$$
\chi=\frac{m_{l}}{m_{g}} \sqrt{\frac{\rho_{g}}{\rho_{l}}}=\frac{u_{l}}{u_{g}} \sqrt{\frac{\rho_{l}}{\rho_{g}}}
$$

First, the liquid-only friction factors were calculated using the Darcy-Weisbach equation, with the number of mixers, $N$, replacing the traditional $L / d_{h}$ term (Equations (5) and (6)). The calculated friction factors were then correlated with the Blasius equation (Equation (6)), where $y$ values of 1 and 0 correspond to fully laminar and turbulent flow, respectively. Table 1 lists the resulting fit for each LL-plate, showing greater values of $c$ for the LL-Triangle due to the blunt obstacle but significant and similar levels of turbulence in the liquid phase for both geometries.

$$
\begin{gathered}
\Delta P_{l}=f_{l} N_{\text {mixer }}\left(\frac{\rho_{l} u_{l}^{2}}{2}\right) \\
f_{l}=\frac{\Delta P}{N_{\text {mixer }}} \frac{2}{\rho u_{l}^{2}}=\frac{c}{R e_{l}^{y}}
\end{gathered}
$$

Table 1. Correlated Blasius equation parameters and $95 \%$ confidence intervals for LL-Rhombus and LL-Triangle geometries for $214<R e_{l}<856$.

\begin{tabular}{ccc}
\hline Geometry & $c$ & $y$ \\
\hline LL-Rhombus & $3.68 \pm 0.76$ & $0.18 \pm 0.035$ \\
LL-Triangle & $5.01 \pm 0.23$ & $0.18 \pm 0.008$ \\
\hline
\end{tabular}

Alternatively, and analogous to flow in a packed bed, the liquid-only pressure loss can be modeled with a friction factor $\left(f_{l}=f_{\text {lam }} / R e+f_{\text {turb }}\right)$ having contributions from both laminar $\left(f_{\text {lam }}\right)$ and turbulent $\left(f_{\text {turb }}\right)$ flow terms to represent a gradual transitional regime [9]. Despite $R e_{l}$ being 213-856 at the contraction, the laminar contribution to the pressure drop ranges from $8 \%$ to $29 \%$ for both the LL-Rhombus and LL-Triangle, which is relevant to the bubble breakdown mechanism with increasing power dissipation within the bubble flow regime.

Although $\mathrm{Ch}$ typically ranges from 5 to 20 depending on the flow regimes of the gas and liquid phases, many attempts have been made to correlate $C h$ to reactor geometry and flow parameters [16,23,24]. Yue et al. [16] suggest that the effects of gas and liquid mass flux on $\mathrm{Ch}$ are significant in microchannels and used gas-only and liquid-only Reynolds numbers in their model. A similar approach was used in this work (Equation (7)), though the superficial velocity ratio was used in place of the gas Reynolds number, since gas viscosity was not thought to significantly impact the two-phase pressure drop.

$$
C h=\beta_{0} \operatorname{Re}_{l}^{-\beta_{1}}\left(\frac{u_{g}}{u_{l}}\right)^{-\beta_{2}}
$$

The pressure drop data were fit with the Talwar robust regression model as implemented in $\mathrm{MATLAB}^{\mathrm{TM}} 2020 \mathrm{a}$, and the results for each geometry and liquid phase used are shown in Table 2. The impact of geometry on the two-phase friction multiplier for the $\mathrm{CO}_{2}$-liquid water system was insignificant, whereas it is marginal for the $\mathrm{CO}_{2}$-aqueous ethanol system where the pressure loss gap observed in single phase flow is diminished in two-phase flow.

The forecasted values show a good agreement with the experimental results as seen in Figure 9. For all fitted models, the average absolute relative error (AARE) is less than $8.1 \%$ and the maximum error is less than $37 \%$, while the bias factor $F_{m}$ is between 0.96 and 1.04 . 
Table 2. Correlation parameter values and 95\% confidence intervals for the tested geometries and continuous phases. For the $\mathrm{CO}_{2}$-water and rhombus data, $214<R e_{l}<856$ and $0.15<u_{g} / u_{l}<36.5$. For all other data, $214<R e_{l}<428$ and $0.14<u_{g} / u_{l}<18.0$.

\begin{tabular}{ccccc}
\hline Continuous Phase & Geometry & $\boldsymbol{\beta}_{\mathbf{0}}$ & $\boldsymbol{\beta}_{\mathbf{1}}$ & $\boldsymbol{\beta}_{\mathbf{2}}$ \\
\hline \multirow{2}{*}{ Water } & Rhombus \& Triangle & $10,497 \pm 4758$ & $1.02 \pm 0.070$ & $0.58 \pm 0.033$ \\
\hline \multirow{2}{*}{$0.5 \mathrm{wt} \%$ aqueous ethanol } & Rhombus & $68,721 \pm 42,191$ & $1.28 \pm 0.10$ & $0.16 \pm 0.062$ \\
& Triangle & $51,761 \pm 27,724$ & $1.29 \pm 0.091$ & $0.20 \pm 0.052$ \\
\hline
\end{tabular}

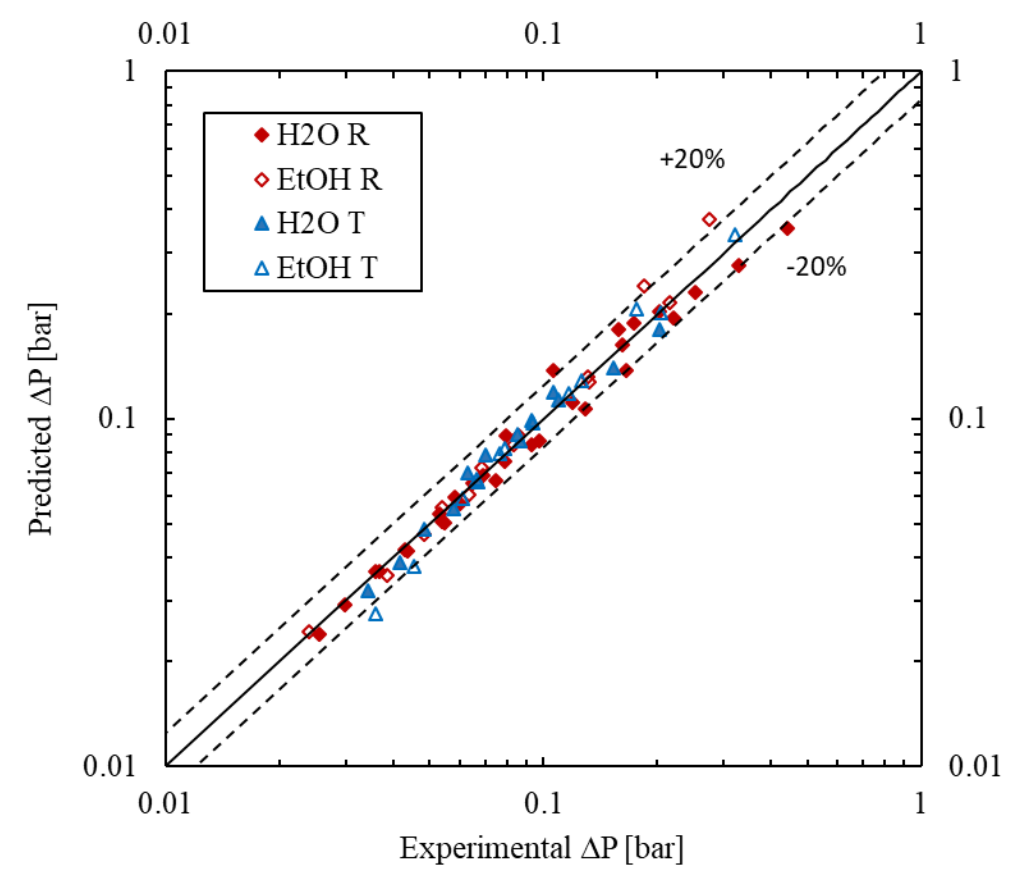

Figure 9. Parity plot of predicted vs. measured pressure drop values.

\subsection{Volumetric Liquid-Side Mass Transfer Coefficient $\left(k_{l} a\right)$}

The interphase mass transfer coefficient for a gas-liquid system is determined through a plug flow material balance over the volume of the reactor. Since nearly pure $\mathrm{CO}_{2}$ was used as the gas phase, all resistance to mass transfer must exist in the liquid phase. Therefore, the volumetric liquid-side mass transfer coefficient, $k_{l} a$, is calculated via a mass balance on the dissolved gas in the liquid phase. If the phase holdups are unknown, then the specific surface area, $a$, is taken per unit volume of reactor according to Equation (8).

$$
k_{l} a\left(C^{*}-C\right)=Q_{l}\left(\frac{d C}{d V_{R}}\right)
$$

Here, $\mathrm{C}$ is the dissolved $\mathrm{CO}_{2}$ concentration in the bulk liquid phase and $\mathrm{C}^{*}$ is the liquid-side interfacial $\mathrm{CO}_{2}$ concentration, which is equal to the equilibrium concentration as determined by Henry's law in Equation (9). At $25^{\circ} \mathrm{C}$, the value of $\mathrm{Heg}_{\mathrm{g}}$ for $\mathrm{CO}_{2}$ in water was taken as $0.034 \mathrm{~mol} /(\mathrm{kg} \cdot \mathrm{bar})$, and measured dissolved $\mathrm{CO}_{2}$ concentrations in the liquid phase at the outlet were below $95 \%$ of saturation for the range of operating conditions.

$$
C^{*}=P_{g} H e_{g}
$$

The integration of (8) over the reactor volume allows for average $k_{l} a$ determination by measuring the inlet and outlet concentrations of the dissolved $\mathrm{CO}_{2}$ concentration according to Equation (10):

$$
k_{l} a=\frac{Q_{l}}{V_{R}} \ln \left(\frac{C^{*}-C_{\text {in }}}{C^{*}-C_{\text {out }}}\right)
$$


where $C^{*}$ is calculated using the average pressure between the inlet and outlet of the reactor, and $C_{\text {in }}$ and $\mathrm{C}_{\text {out }}$ are the dissolved $\mathrm{CO}_{2}$ concentrations in the feed (taken as 0 after measuring via titration) and at the outlet of the reactor, respectively.

\subsubsection{Impact of Operating Conditions}

For deionized water as the liquid phase, as shown in Figure 10a, $k_{l} a$ is greater at higher liquid velocities and increases monotonically with gas velocity before plateauing. Greater liquid velocities enhance bubble breakage and surface renewal via chaotic advection. Similarly, the initial rapid increase in $k_{l} a$ with gas velocity is caused by the corresponding fast increase in power dissipation (i.e., pressure drop) and gas holdup in bubble flow. The later, slower increase in $k_{l} a$ with $u_{g}$ appears to be due to a rise in the length of gas bubbles in slug flow, whereas the plateau is brought on by the onset of annular flow (as seen on flow regime maps of Figure 4), which are both changes in flow regime that decrease the bubble-specific area. The LL-Rhombus also produces higher $k_{l} a$ values than the LL-Triangle for fixed flow conditions. As discussed in Section 3.1, the triangle obstacle is more prone to bubble coalescence due to redirection and recirculation of flow around the obstacle, which causes the onset of slug flow to occur at lower liquid velocities and would thereby decrease the interfacial area available for mass transfer.

Figure 10b, when ethanol is present, shows a similar impact of liquid and gas velocities, where the $k_{l} a$ values eventually reach a plateau at the greater gas velocities for a given liquid velocity. As with the pressure drop data, the impact of obstacle geometry is again marginal. For given fluid velocities and geometry, $k_{l} a$ values were generally higher with ethanol present due to the greater resulting specific interfacial area. Here, the plateau in $k_{l} a$ occurred when the flow resembled a froth where the chaotic eddies in the liquid phase were likely dampened or too small, such that their effective contribution towards surface renewal and interfacial breakdown is decreased $[13,25]$.
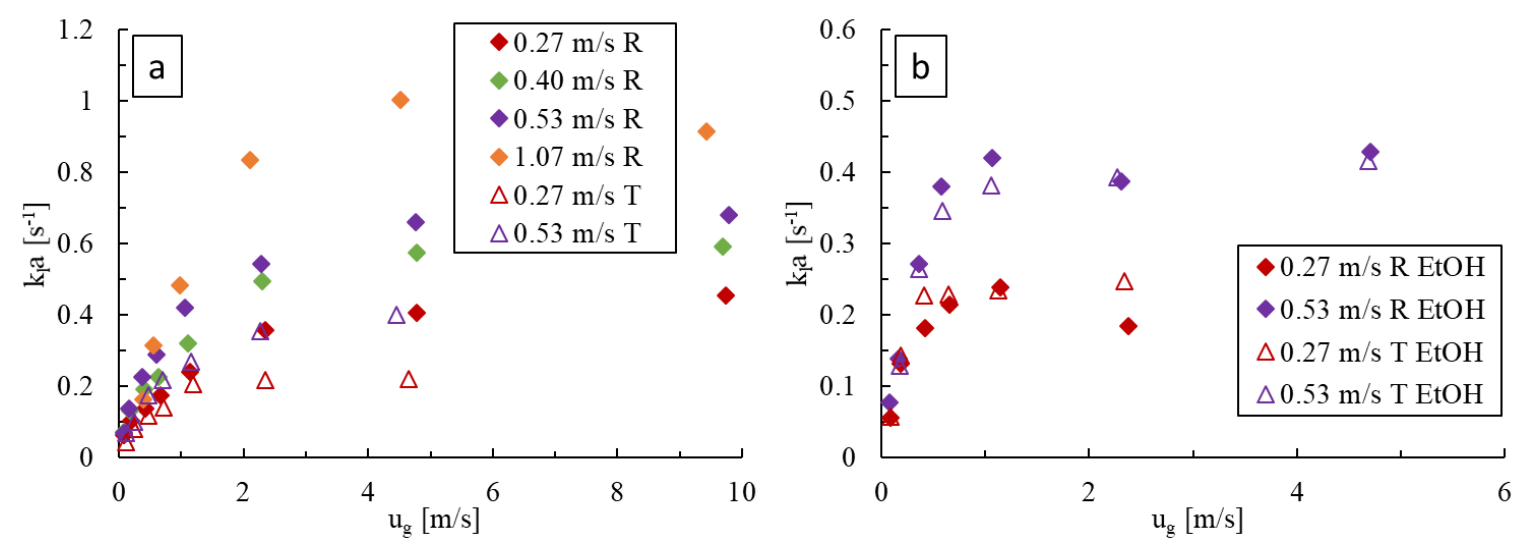

Figure 10. Comparison of $k_{l} a$ at varying gas and liquid flow rates in the LL-Rhombus (R) and LL-Triangle (T) with (a) water and (b) $0.5 \mathrm{wt} \%$ aqueous ethanol as the liquid phase.

The extraction efficiency, $E$, can also be used to examine the relative effects of increasing the gas and liquid velocities on $\mathrm{CO}_{2}$ absorption, and it is calculated according to Equation (11), where $\mathrm{C}^{*}$ is calculated at the outlet pressure.

$$
E=1-\frac{C^{*}-C_{o u t}}{C^{*}-C_{\text {in }}}=\frac{C_{o u t}}{C^{*}}
$$

With deionized water (Figure 11a), increasing the liquid velocity results in a decrease in the extraction efficiency, indicating that the loss in residence time has a greater impact than the increase in $k_{l} a$. Conversely, increasing the gas velocity results in higher extraction efficiencies that reach plateaus coinciding with the flow regime changes seen in Figure 4. These effects are observed in both obstacle geometries, with the LL-Rhombus producing overall higher extraction efficiencies than the LL-Triangle. 
Similar trends are observed when $0.5 \mathrm{wt} \%$ aqueous ethanol is used (Figure $11 \mathrm{~b}$ ). Increasing the liquid velocity again results in a decrease in $E$ due to the loss in residence time, while increasing the gas velocity generates higher $E$ values until the plateau is reached, corresponding to the formation of a froth. With surfactant, however, the effect of geometry is less pronounced than when water alone is used, and both reactors produce similar extraction efficiencies over the range of flow rates tested.
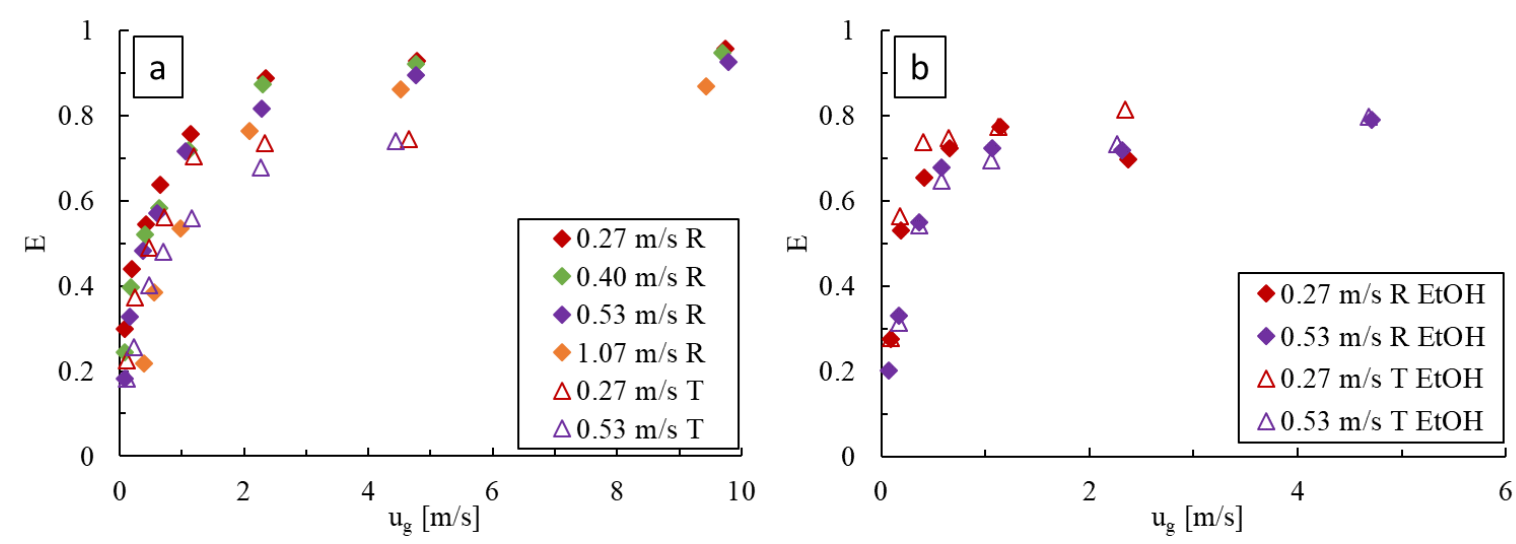

Figure 11. Comparison of the extraction efficiency, $E$, at varying gas and liquid flow rates in the LL-Rhombus (R) and LL-Triangle (T) with (a) water and (b) $0.5 \mathrm{wt} \%$ aqueous ethanol as the liquid phase.

\subsubsection{Model}

The $k_{l} a$ can be modelled as a function of power dissipation, $\epsilon$, and the superficial velocity ratio, using Equation (12) [6].

$$
k_{l} a=\beta_{3} \epsilon^{\beta_{4}}\left(\frac{u_{g}}{u_{l}}\right)^{\beta_{5}}
$$

The parameter $\beta_{3}$ correlates positively with conditions favouring interfacial area creation, such as low interfacial tension. For dense bubbly flow dispersed by isotropic turbulent flow, the value of $\frac{a}{\varepsilon_{g}}$ is proportional to $\epsilon^{0.4}\left(\frac{u_{g}}{u_{l}}\right)^{-0.6}$ [13]. Furthermore, $k_{l}$ has been found to be proportional to $\epsilon^{\sim 0.25}$ for bubble columns and aerated stirred vessels [26], and the gas holdup, $\varepsilon_{g}$, has been found proportional to $\left(\frac{u_{g}}{u_{l}}\right)^{\sim 1.2}$ for the Corning ${ }^{\mathrm{TM}}$ Advanced-Flow ${ }^{\mathrm{TM}}$ reactor for $0.3<\frac{u_{g}}{u_{l}}<6.7$ [6]. The combined effect on $a$ and $k_{l}$ would then yield $\beta_{4} \approx 0.65$ and $\beta_{5} \approx 0.6$.

The power dissipation is calculated from the pressure drop using the following equation, assuming no slip between the phases.

$$
\epsilon=\frac{\Delta P_{T P F} Q_{t}}{\rho_{l} V_{R}} .
$$

The parameters of the $k_{l} a$ model described by Equation (12) were fitted to the bubble flow regime data, where the $k_{l} a$ had not yet plateaued. Considering the confidence intervals for the model parameters, the data of all four combinations of liquid phases and reactor geometries were ultimately pooled, suggesting that the obstacle shape and presence of ethanol have statistically marginal effects on the values of $k_{l} a$ for a given flow superficial velocity ratio and power dissipation. The resulting parameter values are given in Table 3, along with the upper and lower 95\% confidence intervals. The associated parity plot is presented in Figure 12, where the AARE is $13.9 \%$ and the bias factor $F_{m}$ is 1.05 . Furthermore, the value of $\beta_{4}$ is 0.55 , close to the expected value of 0.65 discussed earlier, indicating that the power dissipation model approach is appropriate. 
Table 3. $k_{l} a$ model fits and $95 \%$ confidence intervals for LL-Rhombus and LL-Triangle with water and $0.5 \mathrm{wt} \%$ aqueous ethanol as the liquid phases over the ranges of $0.565<\epsilon<6.91 \mathrm{~W} / \mathrm{kg}$ and $0.14<u_{g} / u_{l}<0.56$.

\begin{tabular}{cccc}
\hline Parameter & $\boldsymbol{\beta}_{3}$ & $\boldsymbol{\beta}_{\mathbf{4}}$ & $\boldsymbol{\beta}_{\mathbf{5}}$ \\
\hline Value & $0.124 \pm 0.022$ & $0.55 \pm 0.12$ & $0.41 \pm 0.11$ \\
\hline
\end{tabular}

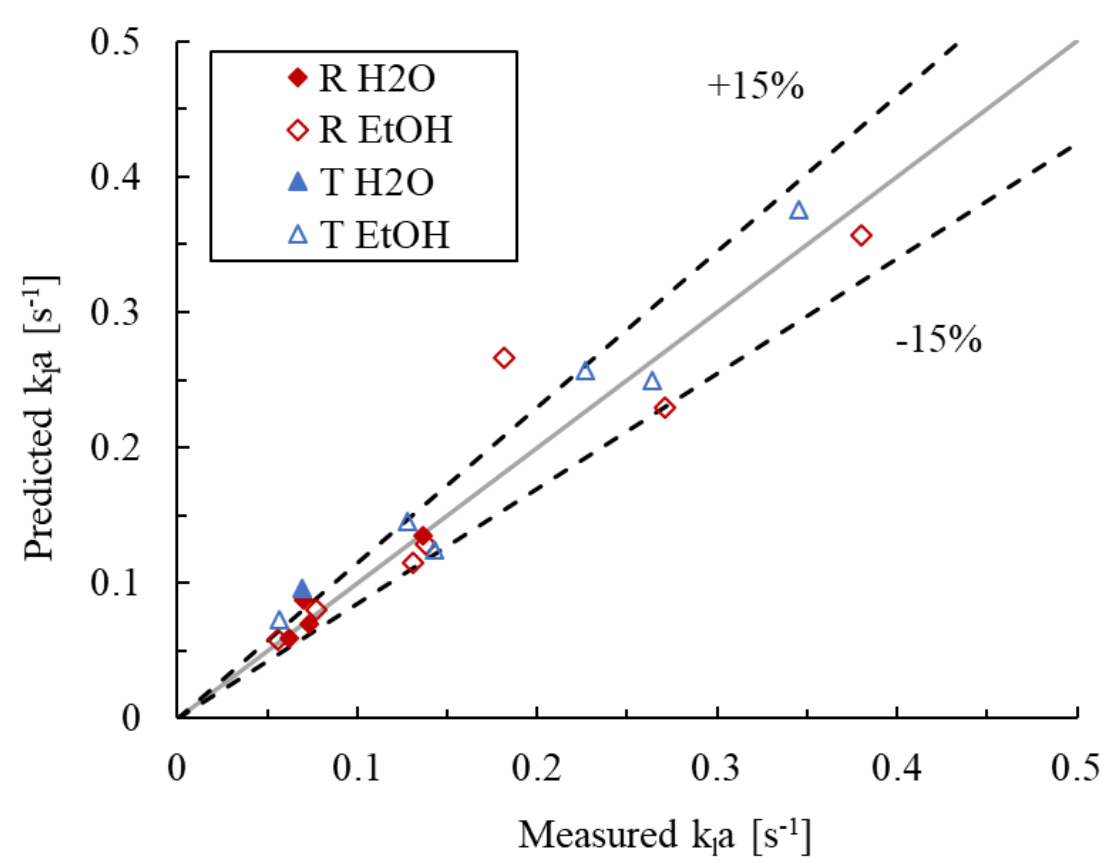

Figure 12. Parity plot of the predicted vs. measured $k_{l} a$ values in the bubbly flow regime.

\section{Conclusions}

With a flowing $\mathrm{CO}_{2}$-water mixture, the LL-Rhombus and LL-Triangle produce flow regime maps comparable to those of microchannels with a hydraulic diameter of a similar size to the contraction of the LL-Reactors. However, the unique geometry decreases the range of slug flow in favor of bubble flow for low gas velocities and in favor of annular flow for high gas velocities. The LL-Rhombus is favorable to the LL-Triangle from a flow morphology perspective, since the more gradual deviation of flow around the obstacle lowers the opportunity for bubble re-coalescence. Furthermore, the LL-Rhombus is generally able to achieve higher $k_{l} a$ values at lower pressure drops for a given flow rate than the LL-Triangle. Finally, the addition of ethanol surfactant to the liquid water caused bubble flow to be present at every operating condition tested.

The Lockhart-Martinelli two-phase pressure drop model is accurate for each data set studied (AARE $<8.1 \%$ ), including for the frothy flow resulting from the aqueous ethanol, but it is limited to the fitted parameters, which are specific to the combination of phases and geometries. A power dissipation-based $k_{l} a$ model was shown to be accurate in predicting interphase mass transfer rates within the bubble flow regime for all flow systems (AARE $<13.9 \%$ ), with the exponential fit of the power dissipation term similar to the expected value based on isotropic turbulent bubble breakage.

Author Contributions: Conceptualization, B.J.D., D.M.R., and A.M.; methodology, B.J.D., F.M., J.B.H., D.M.R., and A.M.; formal analysis, B.J.D., F.M., and J.B.H.; writing—original draft preparation, B.J.D., F.M.; writing-review and editing, B.J.D., F.M., J.B.H., D.M.R., and A.M.; project administration, D.M.R. and A.M.; All authors have read and agreed to the published version of the manuscript.

Funding: The authors thank Lonza and the Natural Sciences and Engineering Research Council of Canada, including the CREATE Program in Continuous Flow Science, for their financial contribution.

Acknowledgments: The authors thank Jacob Mach for his scientific contributions. 
Conflicts of Interest: The authors declare no conflict of interest.

\section{Abbreviations}

Nomenclature (units):

a Bubble interfacial area per unit reactor volume $\left[\mathrm{m}^{2} / \mathrm{m}^{3}\right]$

AARE Average absolute relative error $\left(\frac{1}{n} \sum_{i=1}^{n} \frac{\left|\operatorname{Pred}_{i}-E x p_{i}\right|}{E x p_{i}} \times 100 \%\right)[\%]$

c Parameter in Equation (6) [-]

C Concentration $\left[\mathrm{mol} / \mathrm{m}^{3}\right]$

$C^{*} \quad$ Equilibrium concentration $\left[\mathrm{mol} / \mathrm{m}^{3}\right]$

Ch Chisholm parameter [-]

$d_{h} \quad$ Hydraulic diameter of channel [m]

E Extraction efficiency [-]

Eo Eötvös number [-]

$f_{l} \quad$ Liquid phase friction factor [-]

flam Laminar friction factor contribution [-]

$f_{\text {turb }} \quad$ Turbulent friction factor contribution [-]

$F_{m} \quad$ Bias factor $\left(\exp \left[\frac{1}{n} \sum_{i=1}^{n} \ln \left(\frac{\text { Pred }_{i}}{\text { Exp }_{i}}\right)\right]\right)[-]$

$g \quad$ Gravitational constant $\left[\mathrm{m} / \mathrm{s}^{2}\right]$

$\mathrm{He} \quad$ Henry's constant [mol/(kg.bar)]

$k_{l} a \quad$ Volumetric liquid-side mass transfer coefficient $\left[\mathrm{s}^{-1}\right]$

$(\Delta) \mathrm{L} \quad$ Length of channel $[\mathrm{m}]$

$m \quad$ Mass flow rate $[\mathrm{kg} / \mathrm{s}]$

AARE Average absolute relative error $\left(\frac{1}{n} \sum_{i=1}^{n} \frac{\left|P_{i}-E_{i}\right|}{E_{i}} \times 100 \%\right)[\%]$

$N_{\text {mixer }} \quad$ Number of mixers [-]

$P \quad$ Pressure $[\mathrm{Pa}]$

$\triangle P \quad$ Pressure drop $[\mathrm{Pa}]$

$Q \quad$ Volumetric flowrate $\left[\mathrm{m}^{3} / \mathrm{s}\right]$

Re Reynolds number [-]

$u \quad$ Superficial velocity $[\mathrm{m} / \mathrm{s}]$

$V_{R} \quad$ Reactor volume $\left[\mathrm{m}^{3}\right]$

$w \quad$ Width of channel [m]

y $\quad$ Parameter in Equation (6) [-]

Greek Symbols [units]

$\beta \quad$ Fitting parameter [-]

$\delta \quad$ Channel height [m]

$\epsilon \quad$ Energy dissipation rate [W/kg]

$\varepsilon_{g} \quad$ Gas holdup [-]

$\rho \quad$ Density $\left[\mathrm{kg} / \mathrm{m}^{3}\right]$

$\Delta \rho \quad$ Difference in density between liquid and gas $\left[\mathrm{kg} / \mathrm{m}^{3}\right]$

$\sigma \quad$ Surface tension [N/m]

$\phi^{2} \quad$ Two-phase friction multiplier [-]

$\chi \quad$ Martinelli parameter [-]

Indices

g Gas phase

$l \quad$ Liquid phase

$t \quad$ Total

TPF Two-phase flow 


\section{References}

1. Gutmann, B.; Cantillo, D.; Kappe, C.O. Continuous-Flow Technology-A Tool for the Safe Manufacturing of Active Pharmaceutical Ingredients. Angew. Chem. Int. Ed. 2015, 54, 6688-6728. [CrossRef] [PubMed]

2. Doyle, B.J.; Elsner, P.; Gutmann, B.; Hannaerts, O.; Aellig, C.; Macchi, A.; Roberge, D.M. Mini-Monoplant Technology for Pharmaceutical Manufacturing. Org. Process. Res. Dev. 2020, 24, 2169-2182. [CrossRef]

3. Hessel, V.; Angeli, P.; Gavriilidis, A.; Löwe, H. Gas-Liquid and Gas-Liquid-Solid Microstructured Reactors: Contacting Principles and Applications. Ind. Eng. Chem. Res. 2005, 44, 9750-9769. [CrossRef]

4. Dencic, I.; Hessel, V. Gas-Liquid Reactions. In Microreactors in Organic Chemistry and Catalysis; Wirth, T., Ed.; Wiley-VCH Verlag GmbH \& Co. KGaA: Weinheim, Germany, 2013; pp. 221-288.

5. Kashid, M.N.; Renken, A.; Kiwi-Minsker, L. Gas-liquid and liquid-liquid mass transfer in microstructured reactors. Chem. Eng. Sci. 2011, 66, 3876-3897. [CrossRef]

6. Nieves-Remacha, M.J.; Kulkarni, A.A.; Jensen, K.F. Gas-Liquid Flow and Mass Transfer in an Advanced-Flow Reactor. Ind. Eng. Chem. Res. 2013, 52, 8996-9010. [CrossRef]

7. Nieves-Remacha, M.J.; Jensen, K.F. Mass transfer characteristics of ozonolysis in microreactors and advanced-flow reactors. J. Flow Chem. 2015, 5, 160-165. [CrossRef]

8. Wu, K.-J.; Nappo, V.; Kuhn, S. Hydrodynamic Study of Single- and Two-Phase Flow in an Advanced-Flow Reactor. Ind. Eng. Chem. Res. 2015, 54, 7554-7564. [CrossRef]

9. Plouffe, P.; Bittel, M.; Sieber, J.; Roberge, D.M.; Macchi, A. On the scale-up of micro-reactors for liquid-liquid reactions. Chem. Eng. Sci. 2016, 143, 216-225. [CrossRef]

10. Plouffe, P.; Macchi, A.; Roberge, D.M. From Batch to Continuous Chemical Synthesis-A Toolbox Approach. Org. Process Res. Dev. 2014, 18, 1286-1294. [CrossRef]

11. Macchi, A.; Plouffe, P.; Patience, G.S.; Roberge, D.M. Experimental Methods in Chemical Engineering: Micro-Reactors. Can. J. Chem. Eng. 2019, 97, 2578-2587. [CrossRef]

12. Wu, B.; Firouzi, M.; Mitchell, T.; Rufford, T.E.; Leonardi, C.; Towler, B. A critical review of flow maps for gas-liquid flows in vertical pipes and annuli. Chem. Eng. J. 2017, 326, 350-377. [CrossRef]

13. Ullmann, A.; Brauner, N. The prediction of flow pattern maps in minichannels. Multiph. Sci. Technol. 2007, 19, 49-73. [CrossRef]

14. Akbar, M.; Plummer, D.; Ghiaasiaan, S. On gas-liquid two-phase flow regimes in microchannels. Int. J. Multiph. Flow 2003, 29, 855-865. [CrossRef]

15. Chinnov, E.; Ron'shin, F.; Kabov, O. Regimes of two-phase flow in micro- and minichannels (review). Thermophys. Aeromech. 2015, 22, 265-284. [CrossRef]

16. Yue, J.; Chen, G.; Yuan, Q.; Luo, L.; Gonthier, Y. Hydrodynamics and mass transfer characteristics in gas-liquid flow through a rectangular microchannel. Chem. Eng. Sci. 2007, 62, 2096-2108. [CrossRef]

17. Mielke, E.; Roberge, D.M.; Macchi, A. Microreactor Mixing-Unit Design for Fast Liquid-Liquid Reactions. J. Flow Chem. 2016, 6, 279-287. [CrossRef]

18. Mielke, E.; Plouffe, P.; Mongeon, S.S.; Aellig, C.; Filliger, S.; Macchi, A.; Roberge, D.M. Micro-reactor mixing unit interspacing for fast liquid-liquid reactions leading to a generalized scale-up methodology. Chem. Eng. J. 2018, 352, 682-694. [CrossRef]

19. Dargar, P.; Macchi, A. Effect of surface-active agents on the phase holdups of three-phase fluidized beds. Chem. Eng. Process. Process Intensif. 2006, 45, 764-772. [CrossRef]

20. Song, S.; Peng, C. Viscosities of Binary and Ternary Mixtures of Water, Alcohol, Acetone, and Hexane. J. Dispers. Sci. Technol. 2008, 29, 1367-1372. [CrossRef]

21. Benedetti-Pichler, A.A.; Cefola, M.; Waldman, B. Warder's method for the titration of carbonates. Ind. Eng. Chem. Ed. 1939, 11, 327-332. [CrossRef]

22. Triplett, K.A.; Ghiaasiaan, S.M.; Abdel-Khalik, S.I.; Sadowski, D.L. Gas-liquid two-phase flow in microchannels-Part I: Two-phase flow patterns. Int. J. Multiph. Flow 1999, 25, 377-394. [CrossRef]

23. Balasubramaniam, R.; Ramé, E.; Kizito, J.; Kassemi, M. Two Phase Flow Modeling: Summary of Flow Regimes and Pressure Drop Correlations in Reduced and Partial Gravity; National Aeronautics and Space Administration: Cleveland, OH, USA, 2006.

24. Ju Lee, H.; Yong Lee, S. Pressure drop correlations for two-phase flow within horizontal rectangular channels with small heights. Int. J. Multiph. Flow 2001, 27, 783-796. [CrossRef] 
25. Hebrard, G.; Zeng, J.; Loubiere, K. Effect of surfactants on liquid side mass transfer coefficients: A new insight. Chem. Eng. J. 2009, 148, 132-138. [CrossRef]

26. Kawase, Y.; Moo-Young, M. Mathematical models for design of bioreactors: Applications of: Kolmogoroff's theory of isotropic turbulence. Chem. Eng. J. 1990, 43, B19-B41. [CrossRef]

Publisher's Note: MDPI stays neutral with regard to jurisdictional claims in published maps and institutional affiliations.

(C) 2020 by the authors. Licensee MDPI, Basel, Switzerland. This article is an open access article distributed under the terms and conditions of the Creative Commons Attribution (CC BY) license (http://creativecommons.org/licenses/by/4.0/). 